\title{
A formação continuada dos professores da educação básica no contexto de um projeto político-pedagógico de matriz transdisciplinar
}

\author{
The continuing education of basic education teachers \\ in the context of a pedagogical-political project with \\ a transdisciplinary matrix
}

La formación continuada de los profesores de la
Enseñanza Básica en el contexto de un proyecto
político-pedagógico de matriz transdisciplinaria

\author{
Claudia Furtado de Miranda, Pura Lucia Oliver Martins, \\ Ivana Suski Vicentin, Carlos Henrique Martins Torra*
}

Pontifícia Universidade Católica do Paraná (PUCPR), Curitiba, PR, Brasil

\section{Resumo}

Este artigo trata do estudo de um projeto político-pedagógico de uma escola da rede particular da educação básica de Curitiba, que se fundamenta em uma matriz epistemológica transdisciplinar, apoiada no pensamento complexo. A investigação, via documentos institucionais e entrevista semiestruturada, realizou o exame das possíveis consonâncias e dissonâncias entre a vertente teórica que fundamenta o projeto político-pedagógico e o que

\footnotetext{
*CFM: Mestre em Educação, e-mail: claudiafurt@gmail.com PLOM: Doutora em Educação, e-mail: pura.oliver@puc.br ISV: Doutora em Educação, e-mail: ivanasv@terra.com.br CHMT: Mestre em Educação, e-mail: ctorra2@hotmail.com
} 
se projeta como perfil dos professores que trabalham neste contexto de formação continuada. Verificamos que o projeto político-pedagógico apresenta boa estruturação em sua base teórica transdisciplinar, entretanto, a formação continuada dos seus professores pode não ser concretizada integralmente devido ao perfil exigido destes profissionais.

Palavras-chave: Formação continuada de professores. Pensamento Complexo. Transdisciplinaridade. Projeto Político-Pedagógico. Educação Básica.

\begin{abstract}
This article deals with the case study of a pedagogical-political project of a basic education private school in the region of Curitiba that is based on an epistemological transdisciplinary matrix supported by complex thinking. The investigation, which was conducted with the use of institutional documents and semi-structured interviews, undertook an analysis of the possible consonances and dissonances between the theoretical axis upon which the political-pedagogical project is based and what is projected as a profile of the teachers working in this context of continuing education. We found that the pedagogicalpolitical project presents a good structure in its transdisciplinary theoretical basis, however, the continuing education of teachers might not be implemented fully due to the profile that is required for these professionals.
\end{abstract}

Keywords: Teacher education. Complex thinking. Transdisciplinarity. Political-pedagogical project. Basic education.

\title{
Resumen
}

Este artículo trata del estudio de un proyecto político-pedagógico de una escuela de la red privada de educación básica de Curitiba que se fundamenta en una matriz epistemológica transdisciplinaria apoyada en el pensamiento complejo. La investigación, a través de documentos institucionales y entrevista semiestructurada, realizó el examen de las posibles consonancias y disonancias entre la vertiente teórica que fundamenta el proyecto 
político-pedagógico y lo que se proyecta como perfil de los profesores que trabajan en este contexto de formación continuada. Se verificó que el proyecto político-pedagógico presenta buena estructuración en su base teórica transdisciplinaria, sin embargo, la formación continuada de sus profesores puede no ser concretada de forma integral debido al perfil exigido de estos profesionales.

Palabras clave: Formación continuada de profesores. Pensamiento Complejo. Transdisciplinariedad. Proyecto Político-Pedagógico. Educación Básica.

\section{Introdução}

Quais as bases conceituais e reflexivas de um projeto político-pedagógico de matriz transdisciplinar ao projetar a formação continuada dos seus professores? Qual o perfil de um educador neste contexto de trabalho? Como uma proposta pedagógica de matriz transdisciplinar cuja raiz epistemológica se apoia no pensamento complexo planeja a formação de seus professores?

O presente estudo situa-se no grupo de pesquisa RIPEFOR da PUCPR (Rede Interinstitucional de Pesquisas sobre a Formação e as Práticas Docentes) e buscou analisar os pressupostos teóricos do Projeto Político-Pedagógico (PPP) de um colégio confessional da rede particular de Curitiba que se embasa em uma matriz transdisciplinar, procurando compreender como se estabelece o trato com o conhecimento e os espaços/tempos de formação continuada dos seus professores e educadores ${ }^{1}$. Com esta intenção, foi necessário compreender (i) as fontes bibliográficas que alicerçam a matriz transdisciplinar e a raiz epistemológica fundamentada no pensamento complexo do referido projeto; (ii) a proposta e os espaços de formação continuada que definem o "perfil" do professor/educador pretendido pela instituição para realizar esta proposta pedagógica.

1 Trataremos por educadores os profissionais que fazem parte das equipes pedagógicas. E por professores, os profissionais que atuam em sala de aula. 
A abordagem da pesquisa é qualitativa, seus fundamentos teóricos baseiam-se no método de investigação crítico-dialético em um estudo de caso. A investigação, via documentos institucionais e entrevista semiestruturada, realizou o exame das possíveis consonâncias e dissonâncias entre a vertente teórica que fundamenta o projeto político-pedagógico (PPP) e o perfil dos professores idealizado pela instituição. Neste caminho, o foco desta pesquisa é sobre a Formação Continuada dos professores e o Currículo Transdisciplinar.

Entendemos a Formação continuada como o movimento vívido da relação entre a prática pedagógica do professor e a sua experiência, entre a teoria e a prática, pois a formação do educador é ininterrupta, repleta de mudanças, permanências e simultaneidades. Neste caminho, esta pesquisa apoia-se nos estudos teóricos de Morin (1998) e Santos (2000) para a compreensão das mudanças paradigmáticas no cenário científico e educacional, como também referencia os estudos de Martins (1996); Cunha (2004); Zabala (2002) e Imbernón (2000) acerca dos debates sobre a formação continuada dos professores nos diversos espaços e tempos formativos a partir da escola.

Este artigo apresenta o desenvolvimento e os resultados da pesquisa subdividos nas seguintes partes: metodologia e o referencial teórico da pesquisa; a relação entre o Projeto Político-Pedagógico de matriz transdisciplinar e a Proposta de Formação Continuada de professores da instituição - lócus da pesquisa; as considerações finais com os resultados.

\section{A Metodologia e referencial teórico}

O interesse por esta pesquisa situa-se na análise de como foi construído um projeto político pedagógico de matriz transdisciplinar para a Educação Básica, seja pela busca de verificação ou não da inovação desta proposta, seja por compreender como se situa a formação continuada dos professores no contexto deste projeto. 
Hoje, muito tem se estudado sobre a importância da "religação dos saberes" e da "reforma de pensamento", tanto para o conhecimento da ciência quanto para o conhecimento escolar. Projeta-se também para a escola da educação básica, via legislação atual, uma aprendizagem integral cujo objetivo central é a formação de todas as pessoas nas dimensões bio, antropo, physis e social. Assim, é fundamental que as disciplinas/ciências e áreas do conhecimento dialoguem com e entre os seus métodos e objetos, para que a visão e o estudo sobre o mundo em suas múltiplas realidades contemplem a relação entre o todo e as partes e vice-versa. Talvez este seja um importante desafio para a educação básica e universitária do século XXI: formar pessoas num contexto planetário, mas que saibam interferir no contexto local na busca da justiça social.

A marca do contexto sociocultural e histórico está presente na Escola e define o tipo de educação, de conhecimento, de autonomia e de responsabilidade que se idealiza e que se busca construir na prática da formação de professores e alunos. Desse ponto de vista, esta relação também constitui a formação continuada dos docentes nas dimensões ética, social, emocional, física e cognitiva (MIRANDA, 2018, p. 43).

Assim sendo, foi importante compreender como se deu a história, a intenção educativa e o modo de viabilização do projeto político pedagógico da Escola. A educação na Escola baseia-se em opções pedagógicas que indicam os objetivos e as maneiras de promoção do desenvolvimento de sujeitos que aprendem em determinado contexto sociocultural. A realidade educativa é concreta e se transforma constantemente em "suas crises, incertezas, pressões sociais e econômicas, relativismo moral, dissoluções de crenças e utopias” (LIBÂNEO, 2005, p. 20).

Para efeito desse estudo, foram analisados os documentos institucionais dos anos de 1997 a 2008. Os materiais tratam do Projeto Político Pedagógico, da Pedagogia Inaciana ${ }^{2}$ e sua relação com a concepção de conhecimento e de método de ensino na Escola. Também descrevem os

2 O termo "Pedagogia Inaciana" tem inspiração cristã, pois o Colégio pesquisado é confessional. No decorrer do capítulo, ampliaremos a explicação sobre seu significado para a proposta educativa da instituição. 
encaminhamentos práticos e a organização das atividades entre as equipes de séries e os professores, bem como entre os docentes da mesma série, da mesma disciplina e entre as séries. Estes documentos expressam o diálogo do Colégio com os professores e indicam o espaço cedido à participação dos docentes, tendo em vista o compromisso com o sentido de autonomia e reflexividade idealizados pela instituição.

A partir da análise documental e de entrevista semiestruturada com um integrante da equipe pedagógica e uma instituição foi possível investigar com mais profundidade como se constituíram as bases conceituais/teóricas do referido projeto.

A opção pelo método dialético nos permitiu pesquisar as diversas fontes documentais por meio do confronto teórico-conceitual e das relações de interdependência entre as mesmas. Neste caso, foi importante destacar e compreender as fontes bibliográficas que dão suporte à fundamentação teórica do projeto político-pedagógico e a sua relação com o projeto de formação dos seus educadores - dentro e fora de sala de aula. Em outras palavras, neste contexto de pesquisa, privilegiamos os conceitos e princípios relacionados ao pensamento complexo com a intenção de verificar, de forma dialógica, os conhecimentos e as propostas de formação dos professores.

A perspectiva crítico-dialética, na qual esta pesquisa se apoia, concebe que a realidade escolar possui situações de conflitos, mudanças e singularidades. É neste processo que os professores se constituem simultaneamente como sujeito e objeto, como produto e produtor do conhecimento educacional ${ }^{3}$, pois não existem respostas universais aos desafios educacionais. Pelo contrário, os professores enfrentam situações com características próprias que exigem respostas reflexivas e pertinentes ao contexto em que surgem as contradições. Pois, como argumenta Imbernón (2000, p. 16) “[...] a aquisição de conhecimentos por parte do

3 Conhecimento educacional: entendido como todo o conhecimento que agrega as teorias e as práticas sobre o currículo, a didática, as relações entre professores e estudantes, entre professores e seus pares, enfim, dos múltiplos contextos educacionais. 
professor está muito ligada à prática profissional e condicionada pela organização da instituição educacional em que esta é exercida".

Mesmo que a pesquisa empírica descrita neste artigo se detenha mais à base teórica sobre a fundamentação da matriz transdisciplinar e a sua relação com as propostas de formação continuada dos professores, sem analisar as estratégias que podem dar consistência ao projeto político-pedagógico da referida instituição, afirma-se que toda proposta educativa é elaborada a partir de uma relação direta com as práticas da escola. Assim sendo, consideramos que toda a teoria é social e histórica e, portanto, possui estreita relação com a prática. A análise da realidade educacional, por ser histórica, constrói teorias que se configuram em determinado tempo e espaço.

A base do método e da metodologia que orientam esta pesquisa se apoiam em pesquisas acadêmicas, que tratam da formação continuada de professores no atual contexto de transição paradigmática ${ }^{4}$, caracterizando novos contornos societários e epistemológicos. Num tempo de transições e de rupturas de ordem política, social, econômica, cultural, existencial e do conhecimento científico, os elementos de permanência não têm assegurado uma compreensão da realidade em que se vive, como comenta Frei Betto (1999, p. 260): "Diria que não estamos vivendo uma época de mudanças. Estamos vivendo hoje, uma mudança de época”.

É neste contexto que se reconfigura a relação entre o conhecimento científico, a verdade, a objetividade e a subjetividade que marcam as transições nos referenciais da ciência e da pesquisa acadêmica. Neste artigo, enfatizamos os estudos de Boaventura Sousa Santos (2007a, 2007b, 2000, 1999, 1989) e de Edgar Morin (2006, 2000, 1998, 1991) e suas respectivas releituras para a pesquisa em educação: estudos que envolvem a formação de alunos e de professores nos diversos espaços de constituição da pessoa, em especial, na escola.

${ }^{4}$ A mudança paradigmática que o texto se refere está inserida em um contexto de transição (societária e científica) e não de rupturas generalizantes com a modernidade, até porque este é um assunto polêmico e em estudo na área acadêmica. 
Nesta direção, concordamos com Santos (2007a) quando alerta sobre a necessidade de se construir uma ciência prudente para um mundo decente voltado para a justiça social e a democracia. Entretanto, a atual transição paradigmática não trata de uma ruptura total entre o moderno, pois todo processo de transição é carregado de mudanças, permanências, continuidades e rupturas.

O conhecimento produzido e fragmentado da ciência, ligado ao Paradigma da Modernidade, implicou e implica, até hoje, em uma educação dicotomizada pelas diferentes áreas do saber e postulada nas verdades sacramentadas dos estudiosos que monopolizam o saber. O resultado desta concepção de conhecimento, de mundo e de educação percebe-se em um projeto reducionista centrado na figura do educador como aquele que reproduz a verdade científica sem considerar o "caráter reconstrutivo do conhecimento" (DEMO, 1997b).

Nesta perspectiva de educação, nem o educador e nem o aluno são sujeitos da tessitura do conhecimento, a educação institucionalizada revela uma utopia míope, pois idealiza um projeto de sociedade igualitária que não é capaz de realizar pela falta de autoria, criatividade, inventividade e autonomia dos sujeitos envolvidos neste processo. Santos (1989) enfatiza que é preciso recuperar os projetos de emancipação do paradigma da ciência moderna num processo de suspeição e de transformação. E para tanto argumenta:

Daí a necessidade da dupla ruptura epistemológica que permita destruir a hegemonia da ciência moderna sem perder as expectativas que ela gera. A nova configuração do saber é, assim, a garantia do desejo e o desejo da garantia de que o desenvolvimento tecnológico contribua para o aprofundamento da competência cognitiva e comunicativa e, assim, se transforme em um saber prático e nos ajude a dar sentido e autenticidade à nossa existência (SANTOS, 1989, p. 42).

Para este autor, as crises no paradigma da Modernidade se evidenciam pelo "rombo do modelo da racionalidade" deste paradigma. As 
crises geradas, tanto no interior, quanto no exterior do paradigma da ciência moderna, possibilitam a tessitura de um novo conhecimento científico e de uma nova relação da ciência com o senso comum.

O desafio central de qualquer teoria que se diga crítica é resgatar a esperança, a solidariedade e a utopia, relacionando as ideias com a ação, o desejo com a experiência e a expectativa com a prática.

Se considerarmos os argumentos teóricos sobre a constituição de um novo paradigma que aproxime a teoria e a prática, a ciência e cultura, Edgar Morin (1998) convoca-nos para uma reforma do pensamento que ele chama de "pensamento complexo". Os princípios da ciência no paradigma da complexidade questionam as certezas e as verdades absolutas do pensamento dedutivo-identitário-cartesiano da Modernidade (Paradigma da Simplificação).

Edgar Morin (2000) defende que o "pensamento complexo" é aquele que não separa, mas que une, que pensa junto, que busca construir as relações necessárias e interdependentes de todos os aspectos da vida humana. Por isso, envolve a concepção de mundo, de vida, de ser humano, de ciência e de educação. Neste sentido, a Complexidade e Transdisciplinaridade são inseparáveis. Para este autor, uma "Revolução de Pensamento" só pode acontecer se for ensinado às próximas gerações o pensar e agir na complexidade, ou seja, unindo a teoria e a prática, a objetividade e a subjetividade, o sujeito e o objeto (reciprocamente), a ciência e a arte, a certeza e a incerteza. Morin (2000) destaca que a reforma do método é inseparável de uma Reforma do pensamento, ela própria inseparável de uma reforma do ensino.

Neste caminho de análise, Nicolescu (2000, p. 15) explica que "a transdisciplinaridade, como o prefixo 'trans' indica, diz respeito àquilo que está ao mesmo tempo entre as disciplinas, através das diferentes disciplinas e além de qualquer disciplina. Seu objetivo é a compreensão do mundo presente, para o qual um dos imperativos é a unidade do conhecimento. A proposta transdisciplinar busca indisciplinar o monopólio das certezas e dos modelos, abrindo espaços para o questionamento, para a inovação e para a criatividade. O papel da ciência e também da escola é integrar, articular e 
refletir sobre os próprios conhecimentos. Por isso, abrange a disciplinaridade, pluridisciplinaridade e interdisciplinaridade. Uma proposta de educação transdisciplinar pode caracterizar de forma diferenciada a concepção de currículo e da formação de professores e alunos.

Tanto Edgar Morin (2006), como Boaventura Sousa Santos (1989), projetam suas teses para o campo educacional com o objetivo de promover uma "nova" busca na construção de um conhecimento simultaneamente multifacetado e integral. Este conhecimento deve ser capaz de destacar as grandes interrogações sobre a possibilidade de conhecer e de ensinar a condição humana (ética do gênero humano) e a concepção de ambiente como um sistema interdependente com os demais sistemas, do qual o ser humano faz parte e é por ele responsável. Estes princípios aproximam a formação continuada dos professores da realidade concreta - dilemas, contradições e desafios - e das inovações educacionais, considerando no estudo do contexto educacional, as práticas e os conhecimentos docentes, a formação política que aproxime a ética às práticas ligadas a justiça social e ambiental.

Nesta direção, Cunha (2004) explica que esta concepção de conhecimento e de postura epistemológica promovem uma ruptura com o paradigma da modernidade, mobilizando as reflexões pedagógicas e

[...] indicando novas formas de organização dos currículos, de compreensão dos espaços de aprendizagem de sala de aula, de incorporação das narrativas de vida como elemento de ancoragem dos novos saberes, nas alterações da relação teoria-prática, do ensino-pesquisa, cultura-ciência, para nomear algumas dimensões fundamentais. Percebe-se que as inovações se materializam pelo reconhecimento de formas alternativas de saberes e experiências, nas quais imbricam objetividade e subjetividade, senso comum e ciência, teoria e prática, cultura e natureza, anulando dicotomias e procurando gerar novos conhecimentos. Essas inovações, entendidas como ruptura paradigmática, exigem dos professores reconfiguração de saberes e favorecem o reconhecimento da necessidade de trabalhar o sentido de transformar, como refere Santos, 'a inquietude' em energia emancipatória [...] (CUNHA, 2004, [s.p.], grifos da autora). 
A realidade educacional é multifacetada e transdisciplinar porque ela é a realidade histórica de sua época e das que as antecederam, é a realidade política, social e econômica que movimenta a formação dos alunos e dos professores, é a relação entre os diferentes campos do conhecimento e dos seus cortes culturais no espaço escolar, é a política de estado e suas relações de poder no campo societário, enfim, estas dimensões acontecem simultaneamente e, portanto, são elementos presentes no contexto de formação continuada de professores.

\section{O Projeto Político-Pedagógico de matriz transdisciplinar e a Proposta de Formação Continuada de Professores}

Os pressupostos teóricos analisados acima são referência para a pesquisa sobre o Projeto Político-Pedagógico de matriz transdisciplinar e as bases da formação continuada dos professores de um colégio particular de educação básica de Curitiba. Desta forma, o estudo a seguir trará, por meio da análise dos documentos institucionais e de entrevista semiestruturada, como uma proposta de matriz transdisciplinar estabelece o trato com o conhecimento e os espaços/tempos de formação continuada dos seus professores. Com esta intenção, retomamos algumas questões relevantes a esta pesquisa: Quais as bases conceituais e reflexivas do projeto político-pedagógico de matriz transdisciplinar neste estudo de caso? Qual o perfil que se espera do professor neste contexto de trabalho? Quais os tempos e espaços destinados para a formação continuada dos professores neste contexto específico?

A preocupação com a formação continuada dos professores e educadores (de diversos setores e funções dentro da escola) é constante na fundamentação da proposta educativa do Colégio - lócus da pesquisa. Os diversos documentos da instituição, em especial os textos elaborados coletivamente pela direção acadêmica, representantes dos diversos serviços — orientação pedagógica, educacional, religiosa e de convivência, além dos 
professores que são supervisores das áreas e disciplinas ${ }^{5}$ —, são muito significativos no tocante às diretrizes, avanços e problemas enfrentados nas propostas e no desenvolvimento das questões pedagógicas. Entretanto, para fundamentar a presente análise buscamos cruzar a fundamentação e as diretrizes do PPP do colégio, com o depoimento de um integrante da equipe pedagógica que vivenciou por mais de uma década a tessitura deste projeto educacional, conforme veremos ao longo deste artigo.

No estudo dos documentos do Colégio é perceptível a busca da construção de um projeto com características próprias e, por isso, o mesmo define a realidade social como centro do projeto educativo. Assim, o projeto do Colégio anuncia que a constante reflexão na e sobre a ação é prerrogativa de cada pessoa e de todos os envolvidos no contexto educativo e histórico. Este processo acontece "num ir e vir dialético onde o pessoal e o coletivo são indispensáveis para a superação de um ensino individualista e liberal-conservador ou de uma massificação generalizada em vista de fins comuns ${ }^{6 ”}$. Neste sentido, a escolarização proposta envolve uma educação que contesta o sistema vigente (já nomeado na década de 1990 de neoliberal), ou seja, esta escolarização critica o desenvolvimento de competências, habilidades e técnicas sem o compromisso como o conhecimento social-histórico.

Nessa proposta, a perspectiva dialética adotada revela a base epistemológica que está inserida na relação entre a seleção dos conteúdos (concepção de conhecimento - o que ensinar) e do método (como ensinar e aprender simultaneamente) no projeto de formação continuada de professores. O projeto do Colégio acentua que o conhecimento é um processo em construção afiançado pela relação dialógica entre a realidade histórica (estudo do contexto), a utopia (compromisso da educação na formação do "homem novo"), o conhecimento científico (metalinguagem

5 Os supervisores são professores que representam o corpo docente das áreas/disciplinas, exercem funções nos encaminhamentos pedagógicos junto à orientação pedagógica de cada unidade de ensino (Educação Infantil, 1a e 2a fase do Ensino Fundamental e Ensino Médio) e por meio destas, junto a direção acadêmica da instituição.

${ }^{6}$ PROJETO Político-Pedagógico do Colégio. Curitiba, 2006. p. 5. Grifos presentes no documento institucional. 
específica de cada disciplina e concepção coletiva de ciência) e os valores e atitudes que fazem parte da formação dos educadores e educandos.

Estes elementos são identificados no projeto pedagógico do Colégio como sujeitos do processo formativo e englobam, simultaneamente: o conhecimento que cada professor tem sobre as disciplinas, as características do processo de aprendizagem e desenvolvimento dos alunos da série, a relação entre metodologia e avaliação, os conhecimentos e as práticas pedagógicas. Essa concepção de construção do conhecimento indica, no projeto pedagógico, os vários eixos do processo formativo no Colégio e, de certa forma, destacam que além dos professores (de todos os educadores) e dos alunos, a realidade histórica, a utopia e o conhecimento científico também são sujeitos deste contexto formativo. Estes sujeitos constituem a "matriz transdisciplinar" do projeto e do currículo da instituição (como veremos mais adiante).

O estudo dos documentos institucionais expressa que o conceito de sujeito epistemológico e histórico se apoia na concepção dialética que fundamenta a relação entre sujeito e objeto. Desta forma, as pessoas transformam a realidade histórica e educacional e se transformam simultaneamente nesta interação. Assim, professores e alunos são sujeitos do processo formativo do contexto escolar.

$\mathrm{Na}$ perspectiva do projeto do Colégio, todas as dimensões do conhecimento educacional que os professores constroem ao longo de sua carreira possuem uma matriz transdisciplinar. Esta, se dá quando os sujeitos do processo formativo compartilham de uma concepção coletiva de ciência em que "[...] as verdades científicas são relativas ao seu tempo e espaço" e, portanto, "a realidade não é pronta, acabada e autônoma"7. Os professores, os alunos e todos os envolvidos no contexto educacional são sujeitos “[...] construtores pessoal e coletivamente dessa realidade e se relacionam, dentro de uma interdependência dialética, com o meio natural, social, político, cultural, econômico e religioso"8. Essa interdependência

\footnotetext{
7 Projeto Político Pedagógico do Colégio pesquisado. Curitiba, 2006. p. 53.

8 Projeto Político Pedagógico do Colégio pesquisado, 2006.
} 
dialética na formação continuada dos professores da instituição é explicitada no depoimento de um dos integrantes da equipe pedagógica do Colégio da seguinte maneira:

O projeto começa a ser construído como projeto pedagógico, com a participação coletiva e individual. Ele vai ser sempre pessoal e coletivo. E tendo nesse contexto, o conceito de uma formação permanente, alguns dirão uma formação continuada, a nossa ideia é ter estratégias e uma elaboração de um projeto que dê conta da formação de um profissional reflexivo por meio do trato com o conhecimento, com o contexto, com o tipo de pessoa que se quer. É preciso ter estratégias para fazer com que esse professor consiga se debruçar sobre a pratica e refletir? ${ }^{9}$.

Em decorrência, esta proposta exige que o educador e, em especial, o professor, seja um sujeito crítico e reflexivo no contexto da sua prática e experiência docente, como também, um estudioso da realidade histórica e educacional na qual está inserido.

O referencial, o paradigma da Pedagogia Inaciana ${ }^{10}$, coloca contexto, reflexão e ação como a trilogia de trabalho. Neste aspecto, o trabalho com o contexto e a experimentação deste contexto como construção de cidadania e de pessoas que estejam a serviço dos outros - a expressão é serviço aos demais, para e com os outros -, funda-se exatamente através de uma experiência direta e indireta com o próprio contexto. Isto se dá através do conhecimento, através de práticas de contato com a questão social, através da análise cada vez mais profunda da experimentação de vivências dos próprios alunos e de postura entre si. E neste caso, o processo de avaliação, que é uma retomada permanente. Em vista disto, por exemplo, nós incorporamos alguns conceitos como: $o$ processo de uma avaliação cumulativa, que é a retomada permanente, é a ideia de espiral. Hoje se fala muito numa visão mais circular e, por causa disto, optaremos pela dialética da complexidade mais tarde $[. . .]^{11}$.

9 Entrevista, 2007.

10 Pedagogia Inaciana faz parte da formação humanista das escolas jesuítas.

11 Entrevista, 2007. 
Neste depoimento, observa-se que a atitude de pesquisa sobre a prática procura pensar o ensino como "atividade social de humanização das pessoas e implica responsabilidade social e ética de dizer não apenas o porquê fazer, mas o que e como fazer" (LIBÂNEO, 2005, p. 20). O projeto mostra que a trilogia de trabalho, inserida na proposta de formação continuada de professores e alunos, (a reflexão, a ação e a avaliação) é pertinente dentro do processo de reflexividade que prioriza o estudo da sociedade, dos conhecimentos acadêmicos e da formação integral da pessoa no contexto da escola.

Consideramos importante destacar que as propostas de ensino inseridas em um projeto emancipatório para formação de pessoas críticas e reflexivas em relação às necessidades de seu tempo e da sua história, tiveram uma inspiração muito forte na Pedagogia do Oprimido de Paulo Freire e na própria Teologia da Libertação dentro da Igreja Católica. Esses ideais se alastraram pela América Latina na década de 70 e 80 do século passado e ainda tem um respaldo político e social muito grande nas Teorias Críticas atuais, principalmente no tocante às censuras ao sistema neoliberal e as suas prerrogativas para a educação (com o devido cuidado de generalizações conceituais e práticas). Esta análise também está presente no depoimento do integrante da equipe pedagógica ao rememorar um pouco da história do projeto pedagógico. Nas palavras dele:

$\mathrm{Na}$ estruturação do projeto pedagógico da escola buscou-se uma articulação entre a proposta pedagógica inaciana, as linhas ou as tendências de educação mais recentes na área progressista ou das teorias ditas "críticas" e, de forma especial, uma inspiração na pedagogia de Paulo Freire. Na verdade, com as duas vertentes: a vertente dita mais laica vinculada com a formação de adultos e a vertente mais situada na própria teologia da libertação ao nível de Igreja, pela própria característica da instituição. Por outro lado, também, a vertente da educação histórico-crítica de forma geral (representada por Saviani e Libâneo). Buscamos uma articulação bastante autodidata da escola no que se referia à criação de um projeto que conseguisse dialogar com o contexto atual, com o tipo de pessoa e sociedade, com uma educação mais crítica e criativa e que também a Companhia de Jesus (jesuítas) apresenta. 
Para viabilizar isso, buscamos os referenciais teóricos da atualidade, tanto epistemológicos, como de estruturação curricular.

Em vista disso, buscou-se a estruturação do projeto curricular que tinha como referência trabalhar o conhecimento como vertente central. Por isto comentei sobre a raiz epistemológica e, através do conhecimento, trazer como sujeitos desse processo de formação das pessoas: o contexto, a cultura, a metacultura da nação em que eles estão inseridos, o tipo de pessoa e de sociedade que se quer e uma visão de educador e aluno reflexivo, crítico e criativo [...] Uma das características da educação libertadora é partir da realidade, ou seja, é partir efetivamente daquilo que o professor traz da universidade - o conhecimento da ciência, da disciplina que ele trabalha, sabendo que é um corte de conhecimento escolar, um corte de conteúdo - e as experiências e saberes práticos desses professores ${ }^{12}$.

A inserção do professor na história da construção do atual projeto pedagógico abriu passos importantes para processo de formação continuada dos professores da instituição, como indica o relato abaixo:

Era possível colocar o professor dentro da discussão de contexto, da discussão política, da discussão da questão da educação, da discussão da pedagogia, da reestruturação e da própria concepção de conhecimento. Por isso é que nós pegamos a vertente epistemológica ${ }^{13}$ de estruturação desse projeto. Por quê? Porque partindo da realidade, que era o domínio que o professor tinha, importava fazer com que o professor tivesse uma noção inteira da ciência que seria de base para o seu trabalho, porque ele poderia fazer um corte de conteúdo muito mais autêntico, muito mais autônomo, muito mais real e com muito mais verdade. Partindo, inclusive, do princípio de que o professor entra em sala de aula e, dentro dela, faz o que acredita o que ele domina e o que

12 Entrevista, 2007.

${ }^{13}$ A vertente epistemológica se fundamenta no estudo da ciência e da realidade histórica, partindo num primeiro momento, da concepção dialética da complexidade (Paradigma da Complexidade), tendo como referência um projeto educativo transdisciplinar. Esta informação consta do Projeto Político Pedagógico do colégio pesquisado. Curitiba, 2016. p. 6. 
ele é capaz de fazer. Então o processo tem como bastante foco de formação esta questão. Dos anos 80 para os 90 , caminhamos para uma explicitação cada vez mais crescente deste projeto, com as características do projeto atual ${ }^{14}$.

A que chamamos a atenção durante a historicização deste estudo de caso são as bases pedagógicas no que se refere ao papel da Escola em relação à sociedade (vice-versa) e do conhecimento com seus postulados de verdade e cientificidade. Este conjunto de questões já era discutido no Colégio na década de 80 e 90, mesmo sem a intencionalidade que ocorria na Universidade, mas com o sentido político do papel da Escola e da educação. Em outras palavras, alguns dos referenciais epistemológicos para as pesquisas acadêmicas atuais já eram discutidos na referida instituição de ensino (ex.: Teoria da Complexidade na transição paradigmática da ciência). Isso é explicitado na citação abaixo:

Partimos da construção de uma epistemologia coletiva como eixo norteador de nosso projeto. Pensamos num trabalho educativo transdisciplinar onde a cosmovisão coletiva (contexto mediato e imediato e visão que temos desse contexto), a utopia (o sonho de pessoa e sociedade que temos em nosso horizonte) e as concepções de ciência e das ciências servem de referenciais, pano de fundo, inspiração e fundamento de toda nossa estruturação educativa, pedagógica e didática. A aprendizagem e o nosso projeto de aprendizagem são decorrências dessa concepção coletiva e é nessa perspectiva que buscamos a contribuição dos mais variados autores e propostas. Nessa mesma perspectiva, defendemos ser a aprendizagem ativa uma exigência de nossa ação educativa e uma decorrência da opção e estruturação epistemológica que construímos. (PROJETO Político Pedagógico do Colégio, Curitiba, 2006, p. 26, grifos presentes no documento original).

O gráfico a seguir mostra o trato com o conhecimento em suas múltiplas dimensões, incluindo a concepção de ciência, de realidade/

14 Entrevista, 2007. 
contexto, de utopia e de educador e educando, que foram sistematizadas nos últimos anos.

Gráfico 1 - Projeto Educativo

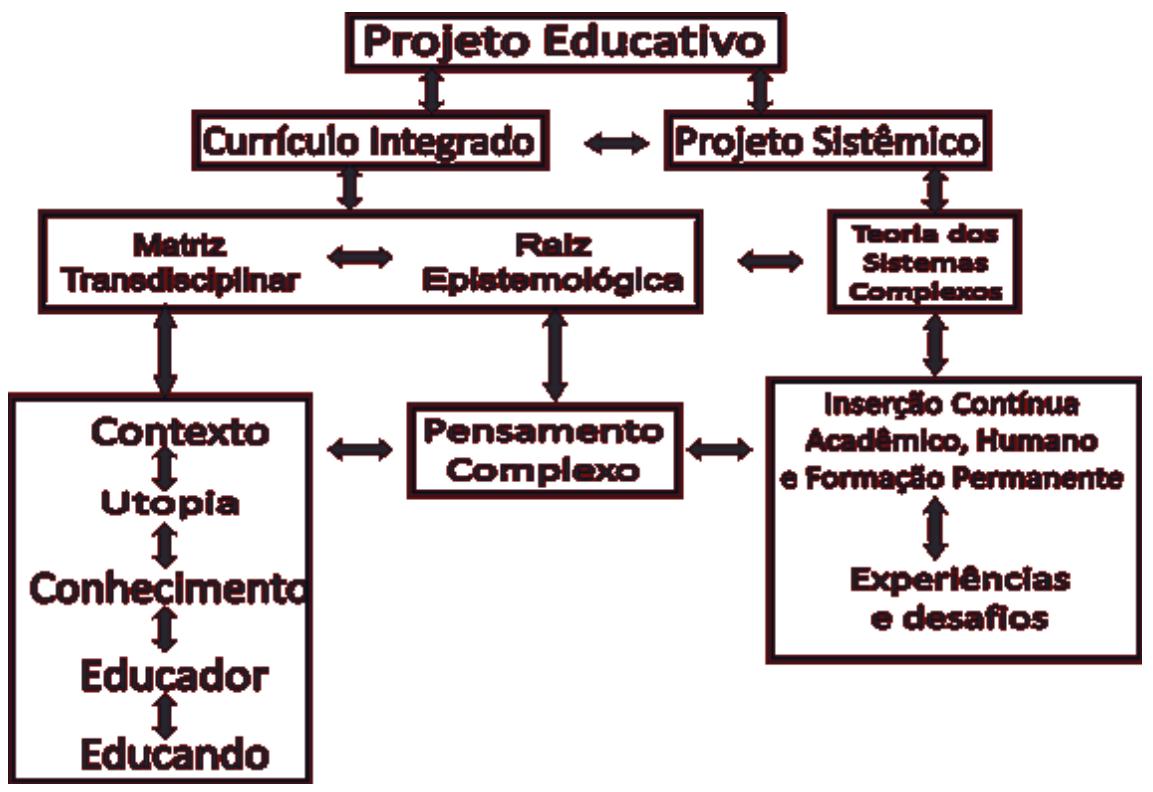

FONTE: PROJETO Político Pedagógico do colégio. Curitiba, 2006, p. 35.

É importante destacar que este gráfico pode ser compreendido por meio da historicização do processo que delineou o atual projeto. Representa o processo histórico de todas as reflexões e ações realizadas com os professores e com os educadores nas últimas décadas (como esclarece o PPP de 2006). Para explicitar os referenciais da proposta e sua relação com a formação continuada de professores, analisamos os seguintes documentos: Currículo Integrado e Projeto Sistêmico, de 2002; Organização Sistêmica e Formação Permanente, de 2004; A Concepção Dialética, de 2000; Da Proposta 
de uma Concepção Coletiva de Ciência, de 2000; Projeto Político-Pedagógico do Colégio (PPP), de 2000 e de 2006, entre outros textos e materiais.

Com base na análise documental, estruturamos a descrição do Projeto de formação continuada do Colégio da seguinte maneira: (a) Matriz transdisciplinar; (b) Raiz epistemológica: o pensamento complexo e a concepção de ciência; (c) Currículo integrado e projeto sistêmico; (d) Passos da formação permanente (continuada).

\section{a) Matriz transdisciplinar}

A base deste projeto educativo, que se coloca como transdisciplinar, se apoia em "cinco sujeitos do processo formativo" elencados da seguinte forma: $O$ contexto: macro e micro: corresponde ao estudo da realidade histórica, social, econômica, cultural e religiosa (local e global), por meio das disciplinas e de todas as atividades formativas realizadas no contexto da escola. A utopia: o horizonte de pessoa e sociedade que se deseja formar, tendo como objetivo a luta por justiça social. O conhecimento: corresponde ao estudo da ciência/disciplina, os conteúdos historicamente acumulados, o contexto formativo, as interferências no acompanhamento de aprendizagem dos alunos. Trata-se em uma concepção de ciência aberta e baseada na dialética da complexidade ${ }^{15}$. Os educadores: todas as pessoas que trabalham na escola, as famílias e os referenciais reflexivos/educativos ativamente participantes na formação. Os educandos: o aluno é simultaneamente educando e educador ativo na construção da sua aprendizagem em relação ao conhecimento das disciplinas curriculares, mas também na sua constituição como pessoa crítica e solidária em relação a si próprio e aos outros.

15 Esta explicação também consta do documento Da Proposta de uma Concepção Coletiva de Ciência, Curitiba, 2000. 


\section{b) Raiz epistemológica: o pensamento complexo e a concepção de ciência}

A raiz epistemológica que fundamenta a proposta educativa do Colégio está relacionada ao currículo integrado, com a matriz transdisciplinar e com os cinco sujeitos do processo formativo. Desse ponto de vista, o conhecimento se fundamenta na raiz epistemológica da complexidade que é ao mesmo tempo meio de intervenção e sujeito constituinte da busca da excelência humana e acadêmica.

\section{c) Currículo Integrado e Projeto Sistêmico}

O currículo integrado proposto pelo Colégio busca uma vertente epistemológica centrada no conhecimento que agrega os estudos do contexto (realidade), do domínio conceitual dos conteúdos escolares e sua construção histórica e das habilidades básicas para o pensamento crítico e criativo. De certa forma, o que se compreende por conhecimento é o estudo sistemático da realidade histórica e educacional e sua relação dialética com os conteúdos das disciplinas, a aprendizagem, o método e a avaliação. O Colégio defende e engloba o currículo aberto e real ${ }^{16}$, realimentado constantemente pela dinâmica de estudos, pela interação com a realidade e pela autonomia dos educadores (professores e setores) na construção coletiva e pessoal de um projeto educativo participativo de formação continuada.

Quando se fala em currículo real e integrado pensa-se no referencial oferecido pelo projeto político-pedagógico e em uma organização curricular aberta, dinâmica e que seja capaz, por um lado, de englobar todas as atividades, práticas e formas educativas/formativas da escola e, por outro lado, que seja expressão real do que esteja acontecendo na instituição. O sentido do integrado é o de "catalisar" todas as experiências e a cultura efetiva e/ou em construção para ser capaz de se tornar

\footnotetext{
${ }^{16}$ Aberto significa a inserção de todos os educadores da instituição e real significa trazer à tona os conflitos
} e as contradições próprias da escola. CURRíCULO Integrado e Projeto Sistêmico. Curitiba, 2002. 
realidade intencional na formação dos sujeitos/agentes envolvidos no projeto e no processo. (CURRÍCULO Integrado e Projeto Sistêmico. Curitiba, 2002. p. 1)

No contexto escolar, lócus da pesquisa, isto significa que o sistema se compõe de unidades complexas (com regras e regulações específicas) que conservam a especificidade em dialogismo com a totalidade do sistema. $\mathrm{O}$ projeto pedagógico da instituição se insere em todos os departamentos e setores, sem perder a especificidade que é unificadora. Nos estudos teóricos ${ }^{17}$ dos docentes da instituição, percebe-se a influência de autores que tratam de analisar com diversos enfoques as mudanças paradigmáticas no campo da ciência, como Morin (1998), Nicolescu (2000), Prigogine \& Stengers (1991), Zabala (2002), Petraglia (2001), Demo (1997 e 2002), cujas leituras nos apropriamos para analisar os documentos do colégio.

Com efeito, verificamos que a proposta teórica de formação de professores no contexto do projeto político-pedagógico do Colégio em estudo, concebe a organização e a dinâmica escolar como um sistema complexo e simultaneamente integrado. Assim, negam-se as teorias e as formas de organizações costumeiramente observadas em diversas instituições, inclusive na escolar, como as organizações estruturalistas e os sistemas de qualidade total. O primeiro hierarquiza os serviços e as funções, e o segundo potencializa e ao mesmo tempo escraviza a criatividade e a diversidade em relação às necessidades mercadológicas.

No entanto, o Colégio mantém no organograma oficial dos serviços uma organização clássica e estruturalista (sistema funcional), composta hierarquicamente pela direção, serviços pedagógicos e administrativos e pelos professores. Esta organização pode ser "transfuncional"18, de acordo com os documentos do Colégio, se o estudo e a comunicação de todos os serviços estiverem integrados às atividades escolares.

17 Estes autores estão presentes nas coletâneas organizadas pela equipe pedagógica e pelos professores para os estudos anuais.

${ }^{18} \mathrm{O}$ conceito de transfuncionalidade é usado nos documentos da instituição para explicitar as possibilidades de os serviços irem além das suas especificidades se compreenderem no contexto do processo formativo de todo o Colégio, a função educativa de cada setor. 
Embora seja difícil perceber pelos materiais analisados a efetivação de toda essa proposta, observa-se no projeto político-pedagógico a previsão de uma organização escolar com espaços de discussão entre os professores, os serviços pedagógicos e administrativos, como também espaços de formação fora do Colégio. Tal organização do trabalho inclui: reunião semanal, seminários de estudo, cursos de Pós-graduação.

Estas estratégias são decorrentes do projeto de formação continuada dos professores e educadores da instituição, sistematizados nos documentos oficiais e chamados de "passos da formação permanente". Estes passos serão analisados abaixo com o objetivo de compreender o que se espera de um professor/educador no contexto de um projeto de matriz transdisciplinar e como se organizam os espaços/tempos para a formação continuada na instituição — lócus da pesquisa.

\section{d) Passos do processo de formação continuada}

Com base na experiência e na história da proposta pedagógica do Colégio, foram sistematizados, em 2004, os passos da formação continuada dos seus educadores. Vale ressaltar que estes passos não foram elaborados a priori do contexto para depois serem implantados. Ao contrário, foram elaborados após vinte anos de construção coletiva. Desta forma, algumas práticas fazem parte da cultura institucional, a exemplo dos seminários internos e reuniões das quartas-feiras à noite, bem como as prioridades de estudos apresentadas em reuniões gerais de início de anos letivos etc.

A seguir, descrevemos os passos formativos propostos em documentos institucionais que penetram na formação docente e buscam possibilitar as categorias formativas destacadas até aqui.

O primeiro passo da formação permanente do Colégio direciona a construção do projeto educativo e pedagógico com a participação efetiva dos educadores, o que inclui as metas e os caminhos a serem seguidos para a inserção profissional dos professores neste contexto pedagógico. No segundo passo, o projeto indica as características centrais dos formadores de formadores e, consequentemente, do que se espera dos professores, ou seja, 
a formação acontece pela pesquisa, criatividade, criticidade e autonomia, a partir da prática de sala de aula e da realidade social. O terceiro passo diz respeito às bases do projeto pedagógico, ou seja, a uma cosmovisão comum baseada na leitura crítica da realidade (no trato com o conhecimento) e, consequentemente, no tipo de educação e de educador que se quer formar. O quarto passo indica a importância de se conhecer o contexto e a cultura escolar, principalmente as suas características, os conhecimentos e os saberes dos educadores. O quinto passo destaca a importância da criação de dinâmicas que possibilitem a construção permanente do currículo e da sua inter-relação com a ação educativa em sala de aula, acentuando, neste sentido, o movimento do trabalho coletivo, do esforço de cada professor/educador no processo reflexivo e intencional sobre a prática pedagógica. O sexto passo se caracteriza pelos eixos norteadores comuns entre teoria a pratica, apoiando-se na relação entre a sistematização escrita e as atividades metodológicas desenvolvidas na escola. O sétimo passo demonstra a preocupação com a formação de um profissional reflexivo diante das diversidades e atribuições que os professores/educadores enfrentam no seu dia-a-dia.

Nesta proposta, de acordo com o PPP, o respeito pela caminhada de cada professor é de importância fundamental para não massificar e homogeneizar a riqueza desta formação. $\mathrm{O}$ trabalho formativo indicado contempla em cada etapa de estudo um tempo de quatro a seis anos.

\section{Considerações finais}

Com base nos estudos descritos e analisados até aqui, entendemos que um projeto sistêmico apoiado em um currículo integrado (real e multirreferencial) para todos os setores e departamentos do Colégio exige a participação ativa de todos os educadores, em especial dos professores.

Em primeiro lugar o currículo integrado ${ }^{19}$ de qualquer projeto educativo que se propõe a ter como base uma matriz transdisciplinar

${ }^{19}$ CURRÍCULO Integrado e Projeto Sistêmico. Curitiba, 2002. 
desafia os professores a compreenderem o que é transdisciplinaridade no plano teórico e no plano prático. Isto implica considerar os conhecimentos escolares com suas inúmeras dinâmicas internas, num contexto de investigação que reconhece a conexão entre a concepção de educação e de conhecimento e entre o método de ensino que o professor utiliza para selecionar os encaminhamentos metodológicos e avaliativos.

Em segundo lugar, o conhecimento transdisciplinar precisa do conhecimento disciplinar. Este conhecimento é construído com o estudo da metalinguagem específica de cada disciplina (conceitos, informações e linguagem) com as realidades planetária, nacional, regional e educacional. É por isso que a transdisciplinaridade envolve a disciplinaridade, a interdisciplinaridade e a pluridisciplinaridade (NICOLESCU, 2000).

Uma proposta curricular transdisciplinar implica também o estudo sistemático (por parte do professor) daquilo que se refere ao conhecimento disciplinar (metalinguagem própria de cada ciência); ao conhecimento pluridisciplinar (como o objeto de estudo de cada ciência pode transitar entre outras áreas do conhecimento); ao conhecimento interdisciplinar (como o método de cada ciência pode transitar entre outras áreas do conhecimento) e ao conhecimento transdisciplinar (como os conhecimentos das diversas disciplinas podem transgredir as barreiras disciplinares). Neste caminho, o conhecimento transdisciplinar convive com a lógica formal, mas avança na leitura dialética do conhecimento científico e da própria realidade, reconhecendo nesta leitura o concreto e o abstrato, o pessoal e o coletivo, a contradição e a pluralidade, a construção e a desconstrução e, finalmente, o tempo e o espaço das memórias individuais e coletivas do professorado.

Em terceiro lugar, a transdisciplinaridade apoia-se no estudo da realidade e da própria ciência como meio de reconstrução do conhecimento e dos sujeitos envolvidos nesta reflexão. Desse modo, contrapõe-se a uma visão estática da sociedade, da ciência e dos seus sujeitos. Isto requer uma leitura epistemológica da prática ${ }^{20}$ (MARTINS, 1996) que contemple o

20 A epistemologia da prática propicia a formação do professor por meio da reflexão crítica que emana do contexto social e político, priorizando e ultrapassando o contexto de sala de aula e possibilitando 
contexto educacional com suas redes de conexões entre sujeito e objeto, entre realidade e conhecimento, entre a neutralidade e o posicionamento e entre a verdade e o provisório.

Esta concepção de conhecimento caracteriza o professor como aquele que pensa a educação de maneira multidimensional, pois educar/ ensinar envolve uma ação reflexiva sobre a concepção que se tem de conhecimento e ciência, de educação e de realidade. Numa proposta transdisciplinar, os professores criam condições para que seus alunos estabeleçam relações entre o conteúdo/conhecimento de uma disciplina e outra, entre os conhecimentos disciplinares e a vida, percebendo a realidade como complexa, multidisciplinar e global (MORIN, 2000).

Com base nos três aspectos analisados anteriormente, um projeto pedagógico com essas características exige um longo processo de reflexão e estudo dos professores sobre os dilemas e contradições do contexto escolar e isto inclui a sala de aula, embora vá mais além. Assim, o projeto de formação de professores do Colégio caracteriza o docente como profissional crítico e autônomo, responsável pela sua prática e leitor permanente da realidade. Essas adjetivações conferem um peso muito grande ao professor, sobretudo se as condições de trabalho e os espaços de discussão coletiva entre o professorado não estiverem assegurados pelo Colégio. Por isso, é de suma importância existir a relação entre a teoria e a prática, entre a proposta e o processo desta formação, levando em conta como os professores relacionam essa fundamentação transdisciplinar, sem desconsiderar as heranças da educação tradicional, tecnicista, escolanovista etc.

Neste sentido, não existe formação de professores e de alunos reflexivos diante de posturas neutras em relação ao conhecimento. A neutralidade nega as experiências que são dinamizadas na vida e no contexto de formação de cada docente, tanto na constituição de sua identidade social quanto profissional. A valorização e a autonomia profissional estão inseridas no contexto histórico, social, político e cultural.

a emancipação dos sujeitos envolvidos no processo educativo. Isto significa que o conceito de epistemologia da práxis (e seus pressupostos de investigação) não esvazia o conhecimento e a teoria. 
Percebemos isso ao analisarmos que a proposta de formação continuada defendida pelo Colégio, lócus desta pesquisa, propõe-se a romper com a racionalidade técnica que coloca o professor como um executor de modelos de ensino previamente definidos pela instituição. A busca de um projeto pedagógico próprio e aberto às necessidades dos professores e alunos pode favorecer que o conhecimento seja construído, principalmente, a partir da escola.

Desse ponto de vista, situamos o projeto pedagógico do Colégio e, em decorrência, a formação continuada de professores num contexto de rupturas e de permanências entre as pesquisas pedagógicas contemporâneas (teoria da complexidade e conhecimento transdisciplinar) e as teorias críticas modernas (conceitos de emancipação humana, autonomia do sujeito, libertação, razão). Isso implica uma mudança de atitude que caracteriza a cultura da escola e a releitura do conhecimento científico/acadêmico pela relação dialógica com o contexto histórico, apoiado na ética e na solidariedade da formação emancipadora do educador e do educando. Assim, percebemos que os grandes desafios desta proposta de formação continuada são os encaminhamentos de mobilização constante do professorado e da equipe pedagógica neste processo de estudos e de desestabilização em relação às formas de fazer e de refletir sobre a prática para que as mesmas não se cristalizem.

Além disso, a fundamentação teórica da proposta pedagógica e de formação continuada do Colégio insere-se em uma realidade com contradições visualizadas nos desafios de uma formação com características humanistas e nas exigências dos resultados acadêmicos. Em outras palavras, a relação entre a teoria e a prática, entre o que se idealiza no projeto de formação de professores (e de alunos), convive com as expectativas dos resultados e das relações de poder dentro e fora da escola.

A relação entre a teoria e a prática é tratada no projeto pedagógico do Colégio como vital para a formação dos seus educadores e coloca a dialogia como eixo de relação entre os estudos científicos e os desafios que emergem da prática. Entretanto, como os professores percebem a relação entre o proposto e o realizável? O que de fato entendem por transdisciplinaridade? O que acreditam de deve ser priorizado em seu processo de 
formação no contexto desta instituição de ensino? Como inserem o diálogo entre a realidade social com o conhecimento disciplinar? Os estudos em seminários internos, reuniões de série e de área podem possibilitar maiores trocas de experiências e de práticas entre os professores, como também das pesquisas teóricas sobre as demandas levantadas?

Um projeto pedagógico com essas características exige um longo processo de reflexão e estudo dos professores sobre os dilemas e contradições do contexto escolar e isso inclui a sala de aula, embora vá mais além. Assim, o projeto de formação de professores do Colégio caracteriza o docente como profissional crítico e autônomo, responsável pela sua prática e leitor permanente da realidade. Essas adjetivações inferem um peso muito grande ao professor, sobretudo se as condições de trabalho e os espaços de discussão coletiva entre o professorado não estiverem assegurados pelo Colégio. Assim é importante investigar os impactos desta proposta pedagógica nas práticas dos professores e demais educadores da instituição.

\section{Referências}

A CONCEPÇÃO Dialética. Curitiba, 2000.

BETTO, F. Um sentido para a vida. Palestra proferida em 20/11/97 na Federação de Comércio do Estado de São Paulo. Revista de Educação CEAP, Salvador, ano VII, n. 27, dez. 1999.

CUNHA, M. I. Sala de Aula: espaços de inovações e formação docente. Revista Educação da PUCRS, ano XXVII, n. 3, n. 53, set./dez. 2004.

CURRÍCULO Integrado e Projeto Sistêmico. Curitiba, 2002.

DA PROPOSTA de uma concepção coletiva de Ciência. Curitiba, 2000.

DEMO, P. Educar pela pesquisa. 2. ed. Campinas: Autores Associados, 1997a. (Coleção Educação Contemporânea). 
DEMO, P. Conhecimento Moderno: sobre a ética e intervenção do conhecimento. Petrópolis: Vozes, 1997b.

DEMO, P. Complexidade e Aprendizagem: dinâmica não linear do conhecimento. São Paulo: Atlas, 2002.

IMBERNÓN, F. Formação docente e profissional: formar-se para a mudança e a incerteza. 6. ed. São Paulo: Cortez, 2000. (Coleção Questões da nossa época, v. 77).

LIBÂNEO, J. C. As Teorias Modernas Revisitadas pelo Debate Contemporâneo na Educação. In: LIBÂNEO, J. C.; SANTOS, A. (Org.). Educação na era do conhecimento em rede e transdisciplinaridade. Campinas, SP: Editora Alínea, 2005. (Coleção educação em debate).

MARTINS, P. L. O. A relação conteúdo-forma: expressão das contradições da prática pedagógica na escola capitalista. In: VEIGA, I. P. A. (Org.). Didática: O ensino e suas relações. Campinas: Papirus, 1996. (Coleção Magistério: formação e trabalho pedagógico).

MIRANDA, C. F. Os referenciais epistemológicos da prática na formação continuada dos professores da $1^{a}$ fase do ensino fundamental. 2008. 183 f. Dissertação (Mestrado em Educação) — Pontifícia Universidade Católica do Paraná, Curitiba, 2008.

MORIN, Edgar. Introdução ao Pensamento Complexo. Coleção: Epistemologia e Sociedade, 1. ed. Lisboa: Instituto Piaget, 1991.

MORIN, E. Ciência com consciência. Edição revista e modificada. 3. ed. Rio de Janeiro: Bertrand Brasil, 1998.

MORIN, E. Os setes saberes necessários à educação do futuro. Trad. Catarina Eleonora F. Silva e Jeanne Sawaya. São Paulo: Cortez, 2000.

MORIN, E. Cabeça Bem-Feita: repensar a reforma, reformar o pensamento. 12. ed. Rio de Janeiro: Bertrand Brasil, 2006.

MORIN, E.; LE MOIGNE, J.-L. A inteligência da complexidade. Trad. Nurimar Maria Falci. São Paulo: Petrópolis, 2000.

NICOLESCU, B. et al. Educação e transdisciplinaridade. Brasília: Edições Unesco, 2000. 
ORGANIZAÇÃO Sistêmica e Formação Permanente. Curitiba, 2004.

PRIGOGINE, I.; STENGERS, I. A Nova Aliança: metamorfose da ciência. Trad. Miguel Faria e M. J. M. Trincheira. Brasília: Editora da UNB, 1991.

PROJETO Político-Pedagógico do Colégio. Curitiba, 2000.

PROJETO Político-Pedagógico do Colégio. Curitiba, 2006.

SANTOS, B. S. Introdução a uma ciência pós-moderna. Rio de Janeiro: Graal, 1989.

SANTOS, B. S. Pela mão de Alice: o social e o político na pós-modernidade. 6. ed. São Paulo: Cortez, 1999.

SANTOS, B. S. Para um novo senso comum: a ciência, o direito e a política na transição paradigmática. A crítica da razão indolente - contra o desperdício da experiência. São Paulo: Cortez, 2000.

SANTOS, B. S. Para um novo senso comum: a ciência, o direito e a política na transição paradigmática. São Paulo: Cortez, 2007a.

SANTOS, B. S. Renovar a teoria crítica e reinventar a emancipação social. São Paulo: Boitempo, 2007b.

ZABALA, A. Enfoque globalizador e pensamento complexo: uma proposta para o currículo escolar. Porto Alegre: Artmed Editora, 2002.

Recebido: 01/12/2017

Received: 12/01/2017

Aprovado: 09/10/2018

Approved: 10/09/2018 